\title{
A Guide to Graduate School Admissions in the Geosciences
}

Samuel J. Smidt, Soil and Water Sciences Department, University of Florida, Gainesville, Florida 32611, USA, ssmidt@ufl.edu; and David J. Gates, Department of Geosciences, University of Arkansas, Fayetteville, Arkansas 72701, USA, djgates@email.uark.edu

\begin{abstract}
While information on pursuing graduate studies is widely available from both web sources and faculty advisers, many prospective students find a lack of organization and consistency in materials. This article seeks to streamline student preparation by providing a guide to graduate program admissions. In addition, we suggest target completion dates and cite open-source material for further documentation. Further, this article helps structure an approach for prospective students while alleviating the demands on faculty by consolidating the advising process.
\end{abstract}

\section{INTRODUCTION}

Total bachelor's degree graduates in the geosciences have doubled over the past decade, increasing competition for available graduate positions (National Center for Education Statistics, 2017). Here, we seek to equip applicants with an annotated timeline (summarized in Fig. 1) and referenced opensource material for extended information, as not all students are equally exposed to this process through their home institution. This guide assumes fall enrollment and is designed for prospective graduate students regardless of current academic level.

\section{TASK 1. GAIN EXPERIENCE}

Successful applicants often highlight past experiences viewed favorably by a graduate selection committee, such as independent research, professional employment, abroad studies, external teaching, or even nontraditional activities. There is no recipe for the perfect applicant, but a common thread is personal growth from past experiences. Many find success conducting research with a faculty adviser at a home institution. Other popular options include the National Science Foundation Research Experiences for Undergraduates program or Fulbright Program, which promote research and education with outside institutions and laboratories. Target date: 1 September of the student's last undergraduate year.

\section{Semester Start Submit Application \\ Acceptance \\ Deadline}

\section{Part}

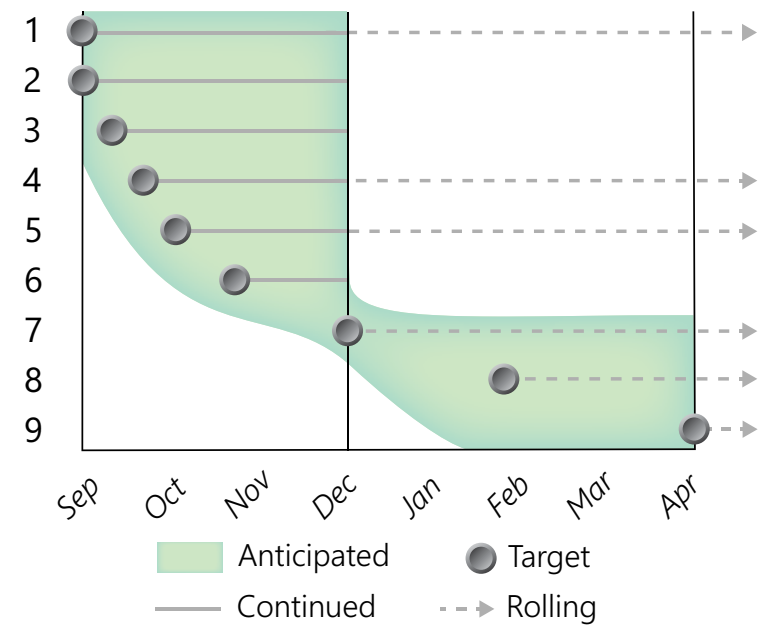

\section{TASK 2. DEVELOP A CV}

Many professional employers require a résumé, but academia operates with the curriculum vitae $(\mathrm{CV})$. In short, a résumé selfpromotes skills and attributes, whereas a $\mathrm{CV}$ highlights what has been accomplished, and it accumulates accomplishments over time. Critical to the $\mathrm{CV}$ at the applicant level are degree and graduation date, relevant coursework and technical knowledge, any research or relevant experience, internships, teaching assistantships, and conference proceedings or publications. Refer to Stark (2015) and Smidt (2018b) for extended details. Target date: 1 September.

\section{TASK 3. TAKE THE GRE}

The Graduate Record Examinations (GRE) is currently the required entrance exam for most graduate programs and is an opportunity to cement a strong application. Graduate departments looking to recruit top applicants may offer scholarships and awards using exam scores as a metric for selection. The GRE is measured across all takers regardless of discipline, so scores in the Quantitative and Writing categories may be weighted more with geoscience programs than Verbal Reasoning. Students may also consider a second attempt; attempts must be at least 21 days apart. Note: Some departments do not require, plan to not require, or will waive the GRE. Refer to Educational Testing Service brochure (ETS, 2017) for extended details. Target date: Early September.

\section{TASK 4. IDENTIFY POTENTIAL ADVISERS}

Selecting a program based on a specific adviser and faculty can be more valuable than selecting one based on institution name alone, and programs should mirror the applicant's professional goals. Department websites or conference proceedings are great

GSA Today, v. 30, https://doi.org/10.1130/GSATG410GW.1. Copyright 2020, The Geological Society of America. CC-BY-NC. 
places to identify target advisers, and faculty members often have personal websites with details on research and position openings. There are hundreds of graduate programs, each with many faculty members (Wilson, 2017), and prospective students should develop a list of target advisers based on interest. Students can also explore network and adviser connections. Target date: Late September, although the list will evolve as new connections are made.

\section{TASK 5. CONTACT POTENTIAL ADVISERS}

A contact e-mail is often necessary, as many prospective students have never communicated with a potential adviser. Here, the goals are to succinctly (1) introduce yourself, (2) state the purpose of your inquiry, (3) communicate your overlapping interests and motivation, and (4) establish a secondary conversation. Some advisers may not respond immediately due to busy schedules, travel, or other various reasons; anticipated reply times are about two weeks. Interested faculty will accept a request for a follow-up conversation while others may not be accepting students. If no response is received after two weeks, a polite follow-up email may be sent. Refer to Smidt (2018a) for a template e-mail. Target date: Late September to mid-October.

\section{TASK 6. NETWORK AT A CONFERENCE}

Attending a professional conference is an efficient way to connect with advisers and graduate students from prospective departments. Students can attend the presentations of prospective advisers and schedule in-person meetings. Department booths are also available in exhibit halls for further information, and prospective students should make their interest known by leaving their contact information with the department sign-in sheet; some advisers may contact students using this list. Target date: October-December, although abstract deadlines are often several months before the conference.

\section{TASK 7. SUBMIT APPLICATIONS}

Applications typically require five things, in addition to supplemental documents specific to an institution: (1) undergraduate transcripts, (2) GRE scores, (3) recommendation letters, (4) a completed application package, and (5) a statement of purpose (i.e., personal statement). There is often an application fee, transcript request fee, and GRE score request fee. Applicants will also be asked to select M.S. or Ph.D. program consideration (Toké and Arrowsmith, 2009). Applications are evaluated as a package; notable deficiencies should be reconciled in the personal statement. Refer to Maher (2017) for extended details. Target date: Deadlines are set by the department and may be as early as 1 December.

\section{TASK 8. VISIT CAMPUS}

Throughout the selection process, applicants may be invited for a campus visit. Campus visits help gain insight into department culture and further develop working relationships with prospective advisers. Most visits include conversations with other faculty and graduate students, a campus tour, and extended time with an adviser. Prospective students often find these visits to be one of the most critical deciding factors in selecting their eventual program. Target date: Early in the spring semester for most institutions.

\section{TASK 9. ACCEPT AN OFFER}

A graduate offer will typically include three things: (1) tuition waver, (2) living stipend, and (3) health insurance. An offer will likely designate a teaching assistantship (TA), research assistantship (RA), or both. Each can provide excellent opportunities, although having time for research is often a main priority for thesis-option students. Once a program has been selected, applicants sign and submit the paperwork. In the case of multiple offers, applicants should notify rejected departments promptly. If selffunded, students may elect to enroll while seeking external scholarships and grants or forgo admission. Refer to Osmond et al. (2015) for extended details. Target date:
15 April for the national acceptance deadline (CGS, 2019).

\section{ACKNOWLEDGMENTS}

We thank past and present faculty advisers, colleagues, and reviewers for helping to develop the context of this guide, including the editors of GSA Today for their valuable feedback.

\section{REFERENCES CITED}

Council of Graduate Schools (CGS), 2019, Resolution Regarding Graduate Scholars, Fellows, Trainees and Assistants: https://cgsnet.org/ ckfinder/userfiles/files/CGSResolution March2019Rv.pdf (last accessed 1 October 2019).

Educational Testing Services (ETS), 2017, The GRE $^{\circledR}$ General Test Accepted at top-ranked schools worldwide: https://www.ets.org/s/gre/pdf/ gre_test_taker_brochure.pdf (last accessed 4 February 2019).

Maher, H.D., Jr., 2017, Applying to graduate schools: http://maps.unomaha.edu/maher/GraduateSchool .pdf (last accessed 4 February 2019).

National Center for Education Statistics, 2017, U.S. Department of Education, Institute of Education Sciences: https://nces.ed.gov/ (last accessed 4 February 2019).

Osmond, J., Meado, A., and Cheney, A., 2015, Selecting and applying to geoscience graduate schools: http://docplayer.net/16107136-Selecting -and-applying-to-geoscience-graduate-schools -by-jonathon-osmond-andrea-meado-and-alex -cheney.html (last accessed 4 February 2019).

Smidt, S., 2018a, Contacting a prospective graduate adviser: https://www.geogradguide.com/ getting-into-grad-school/2018/6/2/contacting-a -prospective-graduate-adviser (last accessed 4 February 2019).

Smidt, S., 2018b, Writing a curriculum vitae: https:// www.geogradguide.com/general-tasks/2018/6/3/ writing-a-curriculum-vitae (last accessed 4 February 2019).

Stark, L., 2015, The Scientist's Conundrum: CV, Resume or Something In-Between: https://ocs.fas .harvard.edu/files/ocs/files/gsas-just-for-scientists -cvs-resumes.pdf (last accessed 4 February 2019).

Toké, N.A., and Arrowsmith, JR., 2009, Selecting and Applying to Geoscience Graduate Schools: http:// arrowsmith310.asu.edu/Lectures/Gradschool_ ApplicationGuide_Toke_Arrowsmith.pdf (last accessed 4 February 2019).

Wilson, C.E., 2017, Directory of Geoscience Departments and Other Geoscience Organizations: Washington, D.C., American Geosciences Institute, 52nd edition.

Manuscript ReCeived 10 April 2019

Revised manuscript ReCeived 2 OCt. 2019

ManUSCRIPT ACCEPTEd 13 Feb. 2020 